\title{
Gastroesophageal reflux disease and dental erosions - A mini review
}

\begin{abstract}
Gastroesophageal reflux disease (GERD) has an established association with dental erosions. Patients with GERD may have chronic exposition of the oral cavity to acid reflux, which may damage the dental surface of either deciduous or permanent teeth. A multidisciplinary approach involving dental surgeons and physicians is needed to diagnose and treat GERD and dental erosions, preferentially in their early stage.
\end{abstract}

Keywords: gastroesophageal reflux disease; dental erosions; dental and medical approach
Volume 7 Issue 5 - 2017

\author{
Daiane C Milani,' Bárbara F Rauber,' \\ Fernando Fornaril, ${ }^{2}$ \\ 'Programa de Pós-Graduação em Odontologia, Universidade de \\ Passo Fundo (UPF), Brazil \\ ${ }^{2}$ Faculdade de Medicina, UPF, Brazil
}

\begin{abstract}
Correspondence: Fernando Fornari, PhD, Programa de Pós-Graduação em Odontologia, Faculdade de Odontologia, Universidade de Passo Fundo, BR285, São José, CEP 99052-900, Passo Fundo-RS, Brazil, Tel +55.54.33168395

Email FernandoFornari@gmail.com; FernandoFornari@upf.br
\end{abstract}

Received: May 28, 2017| Published: September 06, 2017

\section{Introduction}

Gastroesophageal reflux disease (GERD) is a chronic condition that affects between $10-30 \%$ of the population. ${ }^{1}$ The frequent reflux of acid into the esophagus toward the oral cavity may provoke a myriad of troublesome symptoms as well as tissue damage, including dental erosions. ${ }^{2}$ Also known as erosive tooth wear, they result from a physical/chemical process characterized by loss of dental surface secondary to acidification of the oral cavity, without bacterial involvement. ${ }^{3}$ The source of the acid can be intrinsic such as in GERD, or extrinsic, related with the consumption of acidic foods, beverages or drugs. ${ }^{4}$ GERD and dental erosions are frequent in the general population, affecting adolescents and adults. ${ }^{1,5,6}$ Moreover, the management of these conditions requires attention and knowledge from the health professionals, demanding proper information in terms of pathophysiology, diagnosis and treatment. These are the focus of the present mini review.

\section{Pathophysiology}

GERD is characterized by reflux of acid into the esophagus, which can reach the oral cavity. ${ }^{7}$ The most important mechanism is the failure of the anti-reflux barrier, known as lower esophageal sphincter (LES), which is composed by the own esophageal muscle and the diaphragmatic crus. The transient LES relaxation (TLESRs) triggered during post-prandial gastric distension is the main event during which the gastric content is propelled into the esophagus. ${ }^{8,9}$ Furthermore, several risk factors have been associated with GERD, in particular obesity, dietary habits and emotional disturbances. ${ }^{10}$ Dental erosions secondary to GERD occur due to chronic exposition of the oral cavity to acidic juice regurgitated from the stomach. Acid reflux may have the $\mathrm{pH}$ so low as 1.2 , showing therefore a strong potential to decrease oral $\mathrm{pH}$ below 5.5, the critical cutoff for removal of dental minerals. ${ }^{11}$ Oral acidification induces chemical demineralization of teeth, affecting initially the enamel and dentin in advanced stages. ${ }^{12}$ Hence, determining factors of erosive severity include reflux volume and $\mathrm{pH}$, and the way that it reaches the mouth, i.e. liquid regurgitation or belching of acidic gas. ${ }^{13}$

\section{Clinical manifestations}

The typical symptoms of GERD are heartburn and regurgitation. Several atypical complaints may be present, such as chronic cough, chest pain, throat problems and dental erosions. ${ }^{14}$ The most common pattern of GERD-related dental erosions is palatal, particularly from anterior and superior teeth (Figure 1). ${ }^{15}$ Severity of erosive tooth wear in patients with GERD is determined by the duration and intensity of reflux. It is known that dental erosions may become clinically evident after repeated episodes of reflux every week for at least 1 to 2 years. ${ }^{16}$ At oral examination, dental erosions are characterized as subtle and concave loss of dental surface, needing attention and expertise for proper identification. When dentin is affected the dental surface became yellow and the patient may report hypersensitivity or pain, making easier the diagnosis. ${ }^{17}$ The dentist must be aware of cofounding lesions such as abrasion, attrition and abfraction. ${ }^{18}$

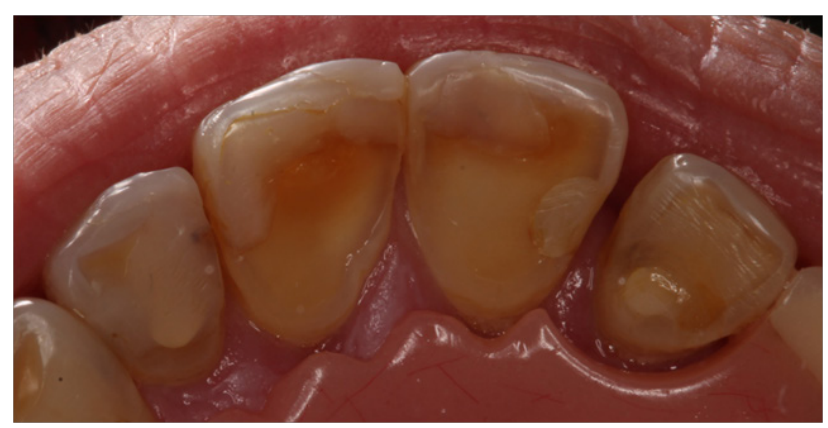

Figure I Erosive tooth wear related with GERD in the palatal surface of upper anterior teeth.

\section{Medical and dental approach}

Confirmation of GERD in the medical practice is performed after detailed consultation, sometimes combined with complementary techniques, particularly endoscopy and ambulatory reflux testing, either $\mathrm{pH}$ only or $\mathrm{pH}$-impedance monitoring. ${ }^{19} \mathrm{~A}$ differential diagnosis with other conditions such as celiac disease must also be considered. ${ }^{20}$. General therapeutic measures include changes in life style and on 
demand or regular use of proton pump inhibitors such as omeprazole.? In the suspicion of dental erosions, the initial management is based on identification and grading of dental damage by an experienced dentist, with investigation of potential causes of extrinsic and intrinsic sources of oral acidification with the help of medical consultation. ${ }^{4}$ In early stages, topical fluorine application may favor dental remineralization and control hypersensitivity, and in advanced cases with substantial loss of dental tissues may be restored with composite resin and porcelain crowns. ${ }^{17}$

\section{Conclusion}

GERD and erosive tooth wear are associated conditions with increasing prevalence worldwide. Reflux of acid contents into the mouth may provoke a slow removal of dental minerals, eroding first the enamel and thereafter the dentin in advances stages. Current management of the two conditions is focused in the combined approach involving medical and dental professionals, with the goal of preventing and treating both GERD and dental erosions. Future research is still needed to identify clinical predictors of dental erosions.

\section{Aknowledgments}

None.

\section{Conflicts of interest}

The authors declare there is no conflict of interest.

\section{Funding}

None.

\section{References}

1. El-Serag HB, Sweet S, Winchester CC, et al. Update on the epidemiology of gastro-oesophageal reflux disease:a systematic review. Gut. 2014;63(6):871-880.

2. Vakil N, van Zanten SV, Kahrilas P, et al. The Montreal definition and classification of gastroesophageal reflux disease:a global evidencebased consensus. Am J Gastroenterol. 2006;101(8):1900-1920.

3. Carvalho TS, Lussi A. Susceptibility of enamel to initial erosion in relation to tooth type, tooth surface and enamel depth. Caries Res. 2015;49(2):109-115.

4. Bartlett DW. The role of erosion in tooth wear:aetiology, prevention and management. International dental journal. 2005;55(4 Suppl 1):277284.

5. Brusius CD, Alves LS, Susin C, et al. Dental erosion among South
Brazilian adolescents:A 2.5-year longitudinal study. Community Dent Oral Epidemiol. 2017.

6. Li W, Liu J, Chen S, et al. Prevalence of dental erosion among people with gastroesophageal reflux disease in China. J Prosthet Dent. 2017; 117(1):48-54.

7. Moayyedi P, Talley NJ. Gastro-oesophageal reflux disease. Lancet. 2006;367(9528):2086-2100.

8. Mittal RK, Holloway RH, Penagini R, et al. Transient lower esophageal sphincter relaxation. Gastroenterology. 1995;109(2):601-610.

9. Kessing BF, Conchillo JM, Bredenoord AJ, et al. Review article:the clinical relevance of transient lower oesophageal sphincter relaxations in gastro-oesophageal reflux disease. Aliment Pharmacol Ther. 2011;33(6):650-661.

10. Kaltenbach T, Crockett S, Gerson LB. Are lifestyle measures effective in patients with gastroesophageal reflux disease? An evidence-based approach. Arch Intern Med. 2006;166(9):965-971.

11. Ranjitkar S, Kaidonis JA, Smales RJ. Gastroesophageal reflux disease and tooth erosion. Int J Dent. 2012;2012:479850.

12. Buzalaf MA, Hannas AR, Kato MT. Saliva and dental erosion. Journal of applied oral science: revista FOB. 2012;20(5):493-502.

13. Dundar A, Sengun A. Dental approach to erosive tooth wear in gastroesophageal reflux disease. Afr Health Sci. 2014;14(2):481-486.

14. Katz PO, Gerson LB, Vela MF. Guidelines for the diagnosis and management of gastroesophageal reflux disease. Am J Gastroenterol. 2013;108(3):308-328.

15. Marsicano JA, de Moura-Grec PG, Bonato RC, et al. Gastroesophageal reflux, dental erosion, and halitosis in epidemiological surveys:a systematic review. Eur J Gastroenterol Hepatol. 2013;25(2):135-141.

16. Ersin NK, Gulen F, Eronat N, et al. Oral and dental manifestations of young asthmatics related to medication, severity and duration of condition. Pediatr Int. 2006;48(6):549-554.

17. Johansson AK, Omar R, Carlsson GE, et al. Dental erosion and its growing importance in clinical practice:from past to present. International journal of dentistry. 2012;2012:632907.

18. Bartlett D. A new look at erosive tooth wear in elderly people. J Am Dent Assoc. 2007;138 Suppl:21S-25S

19. Bredenoord AJ, Smout AJ. Advances in motility testing - current and novel approaches. Nat Rev Gastroenterol Hepatol. 2013;10(8):463-472.

20. Mooney PD, Evans KE, Kurien M, et al. Gastro-oesophageal reflux symptoms and coeliac disease: no role for routine duodenal biopsy. Eur J Gastroenterol Hepatol. 2015;27(6):692-697. 